\title{
QUALITY OF URBAN LIFE: IDENTIFICATION OF LIVABLE URBAN SPACES WITHIN MUMBAI METROPOLITAN REGION
}

\author{
Nikhil Gawai ${ }^{1,}$, Aparna Phadke ${ }^{2}$ \\ ${ }^{1}$ CHM College, Ulhasnagar, India - mr.nikhilgawai@gmail.com \\ ${ }^{2}$ Department of Geography, University of Mumbai - aparna.phadke@geography.mu.ac.in
}

Commission V, WG V/7

KEY WORDS: LANDSAT, green spaces, NDVI, Green space index, livability index, psychological health

\begin{abstract}
:
The quality of urban life has become one of the most pertinent issues in contemporary times in India. There have been several reports published by government and nongovernmental agencies listing out various dimensions of quality of urban life but in a half-hearted manner as some reports have focused just upon the quality of urban air or some governmental reports talk about Human Development Index. There has hardly been any holistic effort to scale the quality of urban life in terms of economic, social, cultural, environmental and psychological well-being. Unless all these parameters are combined, one cannot furnish the livability index of micro urban spaces within major metropolitan regions. The calculation of livability index thus needs to take into account environmental, socio-economic and mental dimensions. The environment related data has been achieved by extracting NDVI through LANDSAT satellite imagery for the month of May, 2018. NDVI has been used for calculating green spaces index. The data related to socio-economic parameters have been collected through primary and secondary sources of data. The data related to psychological health is gathered through questionnaire survey and personal interviews. Ranking based index calculation has been applied to arrive at a common livability index of select sub spaces in Mumbai Metropolitan Region. The outcomes are very interesting and helpful in comparative analysis of select sub-spaces vis-à-vis quality of life. It has also helped in the identification of stressed sub-regional or micro spaces. Such livability index will be highly useful in regional and urban planning. The research aims at calculating livability index for select sub-regional spaces in Mumbai Metropolitan Region.
\end{abstract}

\section{INTRODUCTION}

The quality of life in major metropolitan regions in contemporary times is one of the vital concerns. The spatial pattern of development in metropolitan regions in Global South has been unequal with stark incidences of polarisation. The socioeconomic milieu engaged actively in excluding masses from mainstream development and powered by the affluent classes in diverting resources. The already unequal metropolitan regions in Global South are now exposed to economic globalisation and hence experiencing a massive scale of urban renewal, gentrification and upgradation with speedy infrastructure based in latest technological advancements. These efforts are very similar to efforts of rejuvenating city centres in the developed world. Pertaining to the same specific projects have been introduced to produce and widen the spaces within not only the mother cities but also in the select key spaces in metropolitan regions for the penetration of new industries and commercial activities, with the whole set of their subsidiary and supportive activities like law, advisory, banking and finance, research and development and consultancies (Sassen, 1996). Following the same, unprecedented levels of investment are going into infrastructure to attract international capital and rejuvenate city centres. The requirements of transnational capital and allied activities global in

${ }^{*}$ Corresponding author scope and scale have become the centrepiece of contemporary urban planning in the Global South in general and megacityregions in India in particular (Phadke, 2013). With the consolidation of major cities from the global South into a global urban hierarchy and their role as engines of growth, it has become mandatory for countries in the global South to follow the dictates of global urban policy and specifications about what a global city should look like. It was argued that it was necessary to survive in the quicksilver global economy characterised by its cut-throat interurban competition. In the process, a new centrality is emerging in the form of city-regionalism (a` la Scott, 2001). The interurban competition has opened these globalising city-regions to all kinds of 'new' patterns of development, even when the net effect has been the serial reproduction of science parks, gentrification, world trade centres, cultural and entertainment centres, large interior shopping malls, huge residential and commercial complexes, land and real estate and the like (Harvey, 1989). The abrupt economic restructuring and reorganisation of space in mega cities is intensifying an already distorted pattern of development leading to a complex mix. For example, the rural hinterlands of mega cities continue to observe traditional economic activities like agriculture, but at the same time, this is being penetrated by private edge cities or international schools. These new activities, with their high consumption (water, electricity), create issues regarding rights over the resources which are otherwise inadequate. The long standing stability (stagnancy?) of city-regions has been undermined as their fate now relies upon the deployment, withdrawal and selective penetration of capital that would further decide the upward/ downward mobility of these 
city-regions in global urban hierarchy (Lefebvre, 1991). Pertaining to all these transformations, the urban space in Mumbai is shrinking rapidly for commons and conventional industries. The conventional economic activities are either closed down or relocated to the periphery, for example, relocation of polluting industries in Taloja and Mahul Gaon, Chembur. Simultaneously, relocation of people belonging to lower income and economically weaker sections from demolished slums in Kurla to Mahul Gaon, Chembur. Such relocations are definitely affecting the socialeconomic and environmental wellbeing of the peripheral areas whether this is inner periphery or outer periphery. The rapid conversions of land into built up areas along the Central, Western, Harbour and Trans-Harbour railway lines have been facilitated where it is largely the dispersal of middle, lower and economically weaker sections. The outer peripheries that are largely rural hinterlands, observe the penetration of lavish farmhouses of richer class. All these transformations are occurring without addressing to the basic questions of available basic infrastructural facilities like water, electricity, sanitation and so on. The cultural change that is brought due to such transformation is also responsible for complicating the social relations and introduction of various conflicting situations at personal and community level.

At this juncture, the city regions are facing various problems pertaining to extreme social and economic segregation, spatiosocial polarisation, unequal and class-based access to vital resources and infrastructural facilities, increasing socio-cultural heterogeneity and indifference, erosion of community living, increasing incidences of pollution, escalated levels of intolerance and crime and tremendous deterioration of resources due to various 'development' projects. The urban sustainability is at stake and at this point of time, it is necessary to review the current status of various important growth centres in terms of socioeconomic development, environmental status and mental peace. Largely, the satellite data is used to retrieve physical attributes of the area. But these attributes if combined with socio-economic and psychological characteristics can give a comprehensive understanding of the urban area. The research attempts at combining various dimensions of urban (spatial) development. It would be interesting to know that urban liveability index has been calculated by The central Government of India at a City level and it included broad five broad parameters - stability, healthcare, culture/environment, education, and infrastructure using 30 indicators. The research is carried out for select study regions within MMR.

\subsection{OBJECTIVES}

Following the above discussion the objectives of the present research are set to be - 1) identification of various common socioeconomic variables that are comparable to depict the socioeconomic, environmental and psychological situations, 2) Standardisation of variables to derive a representative index to propose a comparative analysis of select sub-regional spaces for liveability, 3) Collection of data from primary and secondary sources of information that reflects the level of satisfaction and degree of accessibility, 4) Understanding the 'liveability' with the help of green space index, socio-economic index and psychological /mental satisfaction index. 5) Analysing the lacuna in the current method of calculation of 'liveability' index and suggesting alternate methodology that could be applicable in future planning of metropolitan region.

\subsection{STUDY AREA}

The research aims at calculating the liveability index with the remotely sensed data and QGIS. The study area is Mumbai Metropolitan region but the present study is restricted to representative sub-regional spaces. Mumbai Metropolitan Region (MMR) comprises three municipal corporations incorporating 16 municipal towns, 7 nonmunicipal urban centres and 995 villages with 40 planning authorities at various levels. Mumbai Metropolitan Region Development Authority (MMRDA) has been the most influential governmental agency, playing a key role in the process of planning the MMR to become an international financial centre. The emergence of the MMR can be traced back to the $1960 \mathrm{~s}$, when the first administrative effort was made to incorporate the inner periphery of Mumbai into the MMR, followed by the expansion of the MMR to include outer peripheral areas in successive decades. Perhaps unsurprisingly, efforts at metropolitanisation in Mumbai were very strongly influenced by a desire to follow Western models of urbanisation which were often implemented without considering the placespecific challenges in Mumbai generally, or the districts of the MMR more specifically. The Draft Regional Plan proposed the concept of a 'mother city' with satellite towns with the aim of encouraging growth across the MMR through processes of decentralisation. Attempts of industrial dispersal (in distant suburbs like Kalyan, Badlapur and Ambernath) achieved limited success but failed to develop these suburbs as growth poles. The other plans to decentralise activities in Mumbai by developing planned townships (New Bombay) also failed. In post 1990s, the whole region came under the grandiose planning influenced by the fiancé capital. The impact of such planning upon various subregional spaces is varied. But there could be select representative spaces that can be used for analysis. To have proper representation of spaces, in all three sub-regional spaces are selected. The first sub-regional space is one of the biggest planned cities, i.e. Navi-Mumbai. As it is a planned city, infrastructure-wise it stands separate and has better performance in the same. The second study region is Kalyan city and its periphery which was one of the most important port towns historically and now turned into a dormitory suburb of Mumbai. The third case study is Karjat Tehsil which is a typical example of rural hinterland and experiencing huge transformation. There has been huge emphasis upon rural hinterlands in draft regional plan by MMRDA in providing affordable housing to lower income and economically weaker sections.

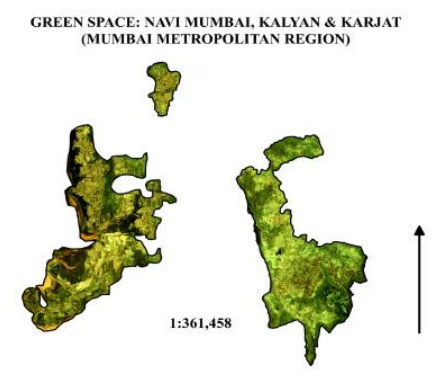

Figure 1 : The Study Area Source : LANDSAT 8 in QGIS 


\subsection{RESEARCH METHODOLOGY AND DATA COLLECTION}

The data has been collected largely through primary sources of information and remote sensing data. Separate questionnaire surveys have been conducted for the select sub-regional spaces. Satellite imagery from Landsat 8 for the month of May, 2018 has been selected for calculation of Green Space. The selection of summer period for extraction of green space was purposely made as the researchers could easily identify and differentiate vegetation from that of agriculture. Then the data is transferred to GIS environment through Quantum GIS and then the analysis is done. The satellite image is vectorised to delimit the green areas. The socio-economic and psychological mapping was done through separately designed questionnaires for all the three select sub-regional spaces. In fact, the survey has been conducted in a great depth. For the current research necessary information has been extracted from survey. In all there are three major categories with 44 indicators in all. At a time, the ethnographic techniques have been used to collect psychological/ mental satisfaction of people staying in these areas. The most vital aspect of this data collection has been the samples have spread over the study areas. But while calculating the indices, the region is considered as a whole.

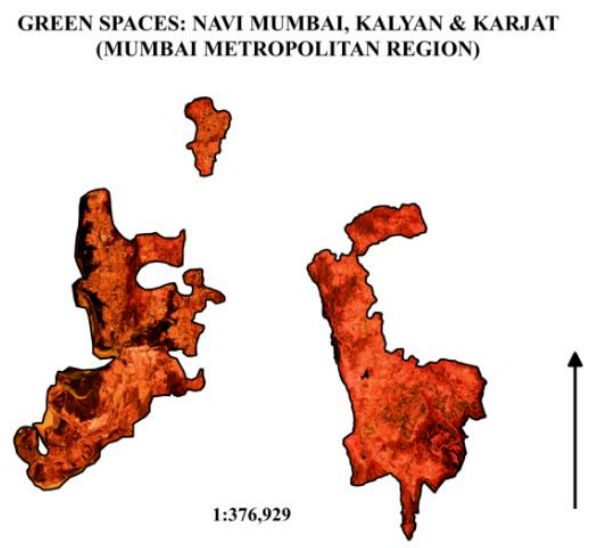

Figure 2 : Green Spaces: Navi Mumbai, Kalyan and Karjat Source : Landsat 8, May,2018

\section{SCALING THE LIVEABILITY OF NAVI MUMBAI, KALYAN AND KARJAT}

Out of three categories of indices, the calculation of green space index has been done by extracting the Normalised Differentiation Vegetation Index for the 3 satellite imageries derived from landsat 8. To achieve accuracy, for all the three imageries first reflectance was derived through the plugin of semi-automatic correction in QGIS. After the imageries were converted into reflectance, the area under the jurisdiction of Mumbai Metropolitan Region was clipped. The areas of sub-regional spaces were also clipped. Following the NDVI classification, the green spaces were digitised to create area vectors.

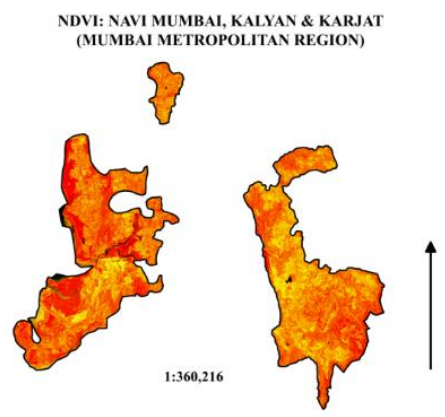

Figure 3 : NDVI for Navi Mumbai, Kalyan and Karjat Source : Landsat 8, May 2018

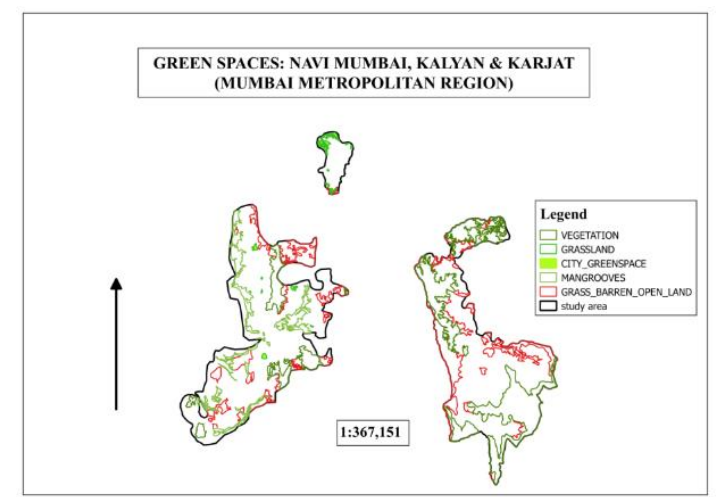

Figure 4 : The Green Spaces in Select Sub-regional Spaces

The area covered with variety of vegetation has been digitised and converted into area vector. Using QGIS, the areas under the green spaces has been calculated. The ratio of total area and green area has been calculated to arrive at a green space index that is standardised to be in the scale of 0 to 1 .

The calculation of socio-economic and psychological/ mental satisfaction index has been standardised to fit into the scale of 0 to 1. The questionnaire was designed in such a way that the answers could be fitted into the scale of 0 to 100 . Each response and the weightage given therein are then averaged to achieve an individual score for each sub-regional space per individual parameter. Then the parameters under each head have been summarised and averaged to arrive at a unique index per broad category. The questionnaire was designed in such a way that the two very important aspects that govern liveability could be achieved - firstly, mental satisfaction which is highly subjective and governed by many psychological factors like relations with neighbour, community life, mental peace and support and secondly, degree of accessibility. The researchers are not here using the data on availability. Something available does not necessarily mean it is accessible. Accessibility has various dimensions in urban context. Location, economic class, caste, gender, religion and political interference are some of the many vital elements that decide the accessibility. When the researchers measured accessibility, they measured it across economic classes, genders and age groups. The same consideration has definitely influence the aggregate value for particular parametric index. The researcher also failed in quantifying certain parameters pertaining to mental satisfaction like accessibility to entertainment facilitiesdrama theatres, multiplexes etc. as it became very subjective and 
had limitations as such facilities are not enjoyed or accessible to all cross sections of society. As already discussed, there have been 44 individual parameters calculated.

\begin{tabular}{|l|r|}
\hline \multicolumn{2}{|c|}{$\begin{array}{c}\text { Psycological/Mental } \\
\text { satisfaction }\end{array}$} \\
\hline Index
\end{tabular}

\begin{tabular}{|l|r|}
\hline \multicolumn{2}{|c|}{ Socio-Economic Index } \\
\hline New Mumbai & 0.9036111 \\
\hline Karjat & 0.3334999 \\
\hline Kalyan & 0.7300277 \\
\hline
\end{tabular}

\begin{tabular}{|l|r|}
\hline \multicolumn{2}{|c|}{ Green Space Index } \\
\hline New Mumbai & $\mathbf{0 . 3 0 6 6 4 5 4 8}$ \\
\hline Karjat & $\mathbf{0 . 5 2 1 0 5 5 0 3}$ \\
\hline Kalyan & $\mathbf{0 . 1 2 8 1 7 1 1 1}$ \\
\hline
\end{tabular}

Table 1 : Composite indices

The table shows the composite scores for all the three broad categories. New Mumbai being the planned city shows highest development and accessibility vis-à-vis socio-economic infrastructural facilities and also has second highest green space which is in distributed manner, thus keeping a better green and built-up space balance. Kalyan being an old municipal town that is victim of unplanned urban growth and development suggests degenerative form of urbanisation and indicate lower levels of socio-economic development. There has been a stark variation in Kalyan East and Kalyan West. Kalyan East is a kind of depressed periphery of old Kalyan and it severely lacks in basic infrastructural facilities. Karjat tehsil absolutely lacks in socioeconomic development as it is largely rural hinterland with comparatively lower population density. Almost half of the karjat tehsil, is dominated by tribal population. The very area is absolutely backward and has major lacunas in infrastructural development. In case of mental satisfaction, Kalyan has little better performance just because, it has basic infrastructure and other facilities not as good as Navi Mumbai but it has better organised community life. As kalyan has been an old city, the social relations and community life has evolved in a unique way. Though it turns out to be city still it has adhere to typical village culture that is rooted in collective living. Karjat tehsil obviously has highest Green space index as this area is still rural and has conventional economic activities and social life but it has lower values for socio-economic index.

\begin{tabular}{|l|r|}
\hline Area & Index \\
\hline New Mumbai & 0.496819 \\
\hline Karjat & 0.377096 \\
\hline Kalyan & 0.388289 \\
\hline
\end{tabular}

Table 2 : Composite Indices
Overall, Navi Mumbai shows the highest composite index in all three sub-regional spaces. The higher value of index is suggestive of better liveability compared to rest two. Navi Mumbai has better levels of socio-economic infrastructure and also better green index. It only lacks in community life and social relations. On security base, Navi Mumbai has better safety and security standards. In all it emerges to be the most liveable space as compared to Kalyan and Karjat.

The aim of this exercise was to create a comprehensive method of calculation of liveability index and that has been achieved to a major extent.

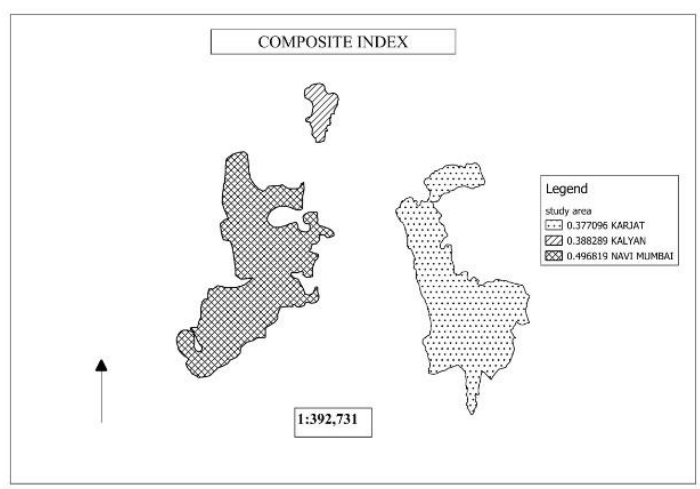

Figure 5 : Liveability Index

\section{Conclusion}

The calculation of liveability index for three select sub-regional spaces could be calculated and represented for the whole region. If we look at these three regions they definitely cover a much larger area and have internal physiographic variations. There is a huge variation also in terms of social and economic characteristic features. These areas are heterogeneous and hence house huge disparity. For example, Airoli and Vashi have population groups belonging to different economic class. The same is also suggestive of different quality and level of infrastructure facilities. Vashi has got better infrastructure than Kalmboli, Airoli and other nodes in Navi Mumbai as Vashi is largely dominated by upper income groups. Kalyan East and Kalyan West have stark variation in terms of infrastructural provision. The same is suggestive of taking up a research at micro-spaces within the subregional spaces and then attempt at liveability index. The same lacuna could also be seen in recently declared liveability index publish by the Global Liveability Index, 2018, with Delhi ranking 112 and Mumbai five places behind at 117. The rankings of 140 global cities, based on their living conditions was released by the Economist Intelligence Unit (EIU) Tuesday, a day after the Indian government released its Ease of Living Index. The EIU is part of UK magazine The Economist and provides forecasting and advisory services through research and analysis (The Indian Express, 2018). 


\section{References}

Nair, S. (2018): Economist Intelligence Unit survey: Delhi ranks 112 on Global Liveability Index, Mumbai 117, The Indian Express

Takeuchi, A ; Cropper, M \& Bento, A (2006) : The Welfare Effects of Slum Improvement Programs The Case of Mumbai, World Bank Policy Research Working Paper 3852, February 2006

Thieme, T; Kovacs, E (2015): Services and Slums: Rethinking Infrastructures and Provisioning across the Nexus, Nexus Network think piece Series, Paper 004 (April 2015), Economic \& Social Research Council
Zhang, Y. (2017): Building a Slum-Free Mumbai? State and Informal Urbanization in India, Paper prepared for Conference on the Political Economy of Contemporary India, January 9-10, 2017, Indira Gandhi Institute of Development Research, Mumbai, India. Research presented in the paper is part of the author's book project on informal housing and urban governance in China, India, and Brazil.

Harvey, D. (1985): Urbanisation of Capital: Studies in History and Theory of Capitalist Urbanisation, John Hopkins University Press, New York

Sassen, S. (1991): The Global City: New York, London, Tokyo, Princeton University Press, New Jersey 